\title{
National Pharmacist Intervention Documentation System at the Ministry of Health in Saudi Arabia
}

\author{
Yousef Ahmed Alomi, (iD The \\ Former General Manager of General \\ Administration of Pharmaceutical \\ Care, The Former Head, National Clini- \\ cal pharmacy and pharmacy practice, \\ The Former Head, Pharmacy R and \\ D Administration, Ministry of Health, \\ Riyadh, SAUDI ARABIA. \\ Saeed Jamaan Alghamdi, General \\ Administration of Pharmaceutical \\ Care, Ministry of Health, Riyadh, \\ SAUDI ARABIA.
}

Radi Abdullah Alattyh, General Administration of Pharmaceutical Care, Ministry of Health, Riyadh, SAUDI ARABIA.

\section{Correspondence:}

Dr. Yousef Ahmed Alomi,

The Past General Manager of General Administration of Pharmaceutical Care, The Past Head, National Clinical Pharmacy and Pharmacy Practice, The Past Head, Pharmacy R and D Administration, Ministry of Health, Riyadh, SAUDI ARABIA.

Phone no: +966504417712

E-mail: yalomi@gmail.com

Received: 01-08-2018;

Accepted: 13-09-2018

Copyright: $\odot$ the author(s),publisher and licensee Pharmacology, Toxicology and Biomedical Reports. This is an open-access article distributed under the terms of the Creative Commons Attribution NonCommercial License, which permits unrestricted non-commercial use, distribution, and reproduction in any medium, provided the original work is properly cited.

This is an open access article distributed under the terms of the Creative Commons Attribution-NonCommercial-ShareAlike 4.0 License

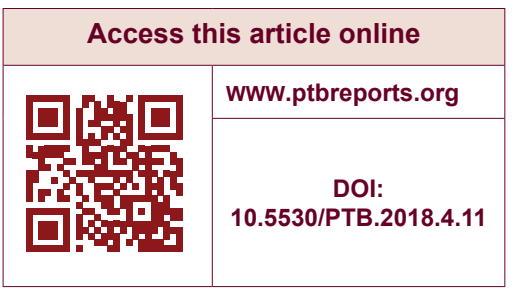

\begin{abstract}
Objective: To review the pharmacist interventions documentation system at the Ministry of Health of Health hospitals and primary care centers in the Kingdom of Saudi Arabia. Method: It is description analysis of pharmacist interventions documentation system at the Ministry of Health of Health institutions. The system analyzed within the Pharmacy strategic plan 2012-2020. The modified pharmacy business model system and Project Management Procedure used in the analysis. Results: Pharmacist intervention documentation system founded with a clear vision, mission and goals. The project had human or economic and other resources clarified in the review. The risk management was described to assure the continuation of the system. Besides, the monitoring and controlling of the system as illustrated. The closing project stage with convention to operation project demonstrated in the Analysis. Conclusion: The Pharmacist interventions documentation system founded and it is considered as part of Pharmacy administration regulations. The documentation of pharmacist interventions has normal development accordingly at all Ministry of Health institutions in the Kingdom of Saudi Arabia.

Key word: Pharmacist Intervention, Pharmaceutical Care, Ministry of Health, Saudi Arabia.
\end{abstract}

\section{INTRODUCTION}

Drug-related morbidity and mortality represent a serious problem both nationally and internationally.1-4 These problems imply a high economic burden in the Kingdom of Saudi Arabia (KSA) and the rest of the world.5,6 Preventing such problems is an urgent requirement of the pharmaceutical healthcare system.7,8 The pharmacist plays a significant role in preventing drug-related problems. Several studies have shown improvement in the clinical outcome of patients after the recommendations and interventions provided by the pharmacist. Moreover, the economic burden can be reduced based on the implementation of recommendations provided by the pharmacist in the KSA.9-12 The documentation system (Appendix 1) of pharmacist interventions started at the Ministry of Health in 1985 at the biggest hospital in Riyadh. This form was updated several times.13-15 In this review, we aimed to explore the national pharmacist intervention documentation system at the Ministry of Health by utilizing the project management tool in Saudi Arabia.

\section{MATERIALS AND METHODS}

\section{Method of Development of the Project}

The clinical pharmacy task force committee consisted of expert people from the pharmacies of the $\mathrm{MOH}$ hospitals to set up a national pharmacist interventions documentation system for the pharmacies of the hospital, PHCs and dental centers. The first author of this article headed the medication safety committee; he conducted regular periodical meetings. The committee unitized and drove the pharmacist interventions of the GAPC and some development at non-MOH hospitals. The draft was prepared by using the international business model, pharmacy guidelines and project management institution guidelines of a new project.16-19 The draft was sent to several reviewers of the Regional Pharmaceutical Care Administration (RPCA). The draft was corrected and updated regularly. Then, the second draft was submitted to the reviewers again for their final comments and approval. This process took around 4 months to prepare the final version. The General Administration of Pharmaceutical Care Administration (GAPC) at the $\mathrm{MOH}$ sent the final document to all the hospitals for implementation. The pharmacist interventions documentation system underwent several phases of development including the initial phase, planning phase, execution phase and monitoring and controlling phase.

\section{Initial Phase}

\section{Assessment Needs}

The pharmacist has a significant role in the pharmacy practices in the KSA, such as the implementation of pharmaceutical care across the country. The pharmacy practice program was established and expanded over the past few years. However, all previous data cannot be known unless it has been published. The role of pharmacist cannot be known without a proper documentation system. One of the essential tools of the documentation was a pharmacist intervention system. Moreover, 
based on the intervention system, the pharmacist's workload needs to be calculated and the economic impact of the pharmacist intervention in the KSA.

\section{Market Analysis}

Several types of pharmacist intervention documentation systems exist in the field of pharmacy. Some documentation systems have all the related information about the project and others have all related information about the requirement. Some institutions have manual pharmacist intervention documentation system, whereas others have electronic pharmacist intervention documentation system. Some institutions have the system connected to the electronic patient profile and have the facility of sending emails to the concerned healthcare providers. The electronic documentation was conducted through the Survey Monkey system for documentation and reporting to all $\mathrm{MOH}$ healthcare institutions.

\section{SWOT Analysis}

In this project, we performed a SWOT analysis of the implementation processes. The strengths of this project were documentation of pharmacist performances, measurements of pharmacist outcome and documentation of pharmacist role. The weak points of this project were time needed for the documentation, need of an electronic method of documentation and healthcare team documentation-related problems. The opportunities for this project were fitting the pharmacy and hospital quantity standards. It supports the New Saudi Vision 2030.20 The threats of this project were the missing follow-up documentation system and the lack of clear explanation in the pharmacy law.

Planning Phase

\section{The Scope of the Project}

The pharmacist intervention documentation system documents any corrections performed on drug therapy mistakes or monitoring. It also includes suggestions made for choosing the best therapy for the patient. The documentation system consists of the name of the clinical activities, type of interventions, the potential of those interventions, acceptance of the interventions from the medical team, medications involved, pharmacist's recommendations and clinical and economic outcome of the interventions.

\section{Vision, Missions and Goals}

The vision of the project is to prepare the best pharmacist intervention documentation system and include all the electronic information that reflects the patient's clinical and economic outcome of the interventions. The mission of this project is to provide a friendly pharmacist intervention documentation system to all pharmacists and pharmacy technicians in the pharmacy departments. The goal of this project is to prepare a standardized system of pharmacist intervention documentation system at $\mathrm{MOH}$ institutions in Saudi Arabia, to calculate pharmacist workload, to measure the clinical and economic outcome of the interventions, to capture the demand of pharmacy staff to monitor the drug therapy related issues.

\section{Project description}

All pharmacists and healthcare providers should follow the policy given below:

1 If any caregiver in the MOH hospital/PHC notices that a patient experiences drug-related problems or need any pharmacist's intervention, then he/she must assess the patient in the following ways:

2 The caregiver should record the assessment in the patient's pharmacist intervention form.

3 The caregiver should notify the patient's attending physician for any action needed. The physician may need to change the therapy and/or provide necessary treatment.
4 The caregiver should notify the nursing shift manager. A clear label/ note on the medical record should be affixed to indicate that the patient has an allergy from such medication.

5 The caregiver should utilize the pharmacist intervention form and complete the following information:

- Patient demographics

- Suspected drug or lab concern

- Concomitant drugs

- Intervention severity codes

- Clinical intervention activity

- Recommendation

- Intervention outcome for recommendations

- Patient outcome

- Pharmacoeconomic impact

- Cost avoidance impact

- Name, profession, address, phone and fax

6 The caregiver should send the completed form to the clinical pharmacy department.

7. While documenting, if the caregiver needs clarification about any item that should be completed, he/she must ask the clinical pharmacy department to assist him in how to complete the documentation of all the required information.

8. The clinical pharmacy department is responsible for sending the completed form (and enter the data in the electronic form in the MOH website) to the GAPC, clinical pharmacy department.

9. The clinical pharmacy department is responsible for keeping all the original completed pharmacist intervention form confidentially.

10. The clinical pharmacy department is accountable to aggregate the data of all the pharmacist intervention reports and formulate a Monthly Pharmacist Intervention Summary Report.

11. The Director of Pharmacy or designee shall review all the monthly reports.

12. The clinical pharmacy department is responsible for submitting the monthly report to the following:

- Quality department

- PTC

- Patient Safety Committee

- Medication Safety Committee

13. The clinical pharmacy department is responsible for submitting report of the independent case to them.

14. An investigation of the pharmacist intervention, especially preventable pharmacist intervention causes and contributing factors should be performed and documented by the clinical pharmacy department in coordination by the affected department(s)/assigned team

15. All necessary action(s) should be taken along with follow-up actions as necessary to prevent further drug-related problems, especially preventable drug-related problems.

\section{Planning Cost Management}

The documentation system requires financial resources for the education and training of the pharmacy staff, outsourcing of electronic database for instant Survey Monkey system and economic factors for the engagement of documentation of interventions. 


\section{Execution Phase}

\section{Management Team}

The management team responsible for the follow-up of the pharmacist intervention documentation system was clinical pharmacy committee. The central committee was designed through the GAPC at $\mathrm{MOH}$; the committee consisted of representatives from each region specialized in clinical pharmacy. A regional committee was established for each region consisting of representatives from each hospital and group PHC. All committees had a monthly meeting to discuss several things related to the clinical pharmacy issues including the pharmacist intervention documentation, analysis of pharmacist intervention clinical outcomes and cost avoidance.

\section{Education and Training}

The project needs regular educational courses for the pharmacists through GAPC at $\mathrm{MOH}$ and RAPC.

\section{Implementation of the Services}

\section{Risk Management}

There are six types of risks: budget risks, scope risks, personal risks, schedule risk, technical risks and quality risks. The project might experience risks such as budget, personnel and quality risks. The project might experience budget risk due to unavailability of the budget for education and training for the pharmacists and for converting the pharmacist interventions manual documentation into the electronic documentation system. The project might be exposed to personnel risks such as shortage of staff with a high workload of documentation pharmacist interventions system. In addition, the pharmacy staff not received education or training about the project. The project might be exposed to quality risks due to the nonqualified pharmacist being available and training in the quality pharmacy tools. The project might experience other technical risks such as unavailability of the electronic system of pharmacist interventions documentation with friendly use.

\section{Monitoring and Controlling Phase}

\section{Project Quality Management}

The documentation system can be used as the Key Performance Indicators (KPIs) for all pharmacy practice programs. The KPIs of the system will be the measure of the adherence and compliance of the documentation system. Another KPI will be the prompt request of the reporting system. Beside, to determine the cost analysis of pharmacist intervention system for each activity.13,14

\section{The Closing of the Project}

The pharmacist interventions documentation system at $\mathrm{MOH}$ institutions is a critical tool to prevent drug-related morbidity and mortality in the KSA. The annual report of pharmacist interventions should be prepared. Healthcare providers should be provided education and training on the documentation system regularly. Further implementation of cost avoidance of Pharmacist interventions in the future. Annual celebration with the members involved in this project must be conducted.

\section{ACKNOWLEDGMENT}

None.

\section{CONFLICT OF INTEREST}

The authors declare no conflict of interest.

\section{ABBREVIATIONS}

MOH: Ministry of Health; KSA: Kingdom of Saudi Arabia; ADR: Adverse drug reaction; KPIs: Key performance indicators; RCA: Root cause analysis; SWOT: Strengths, weaknesses, opportunities and threats; WHO: World Health Organization; SFDA: Saudi Food and Drug Authority; ASHP: American Society of Hospital Pharmacy; PTC: Pharmacy and Therapeutic Committee; RAPC: Regional Administration of Pharmaceutical Care; GAPC: General Administration of Pharmaceutical Care.

\section{ORCID ID}

Yousef Ahmed Alomi (iD https://orcid.org/0000-003-1381-628X.

\section{REFERENCES}

1. 1. Rashed AN, Neubert $A$, Alhamdan $H$, Tomlin $S$, Alazmi $A$, AlShaikh $A$, et al. Drug-related problems found in children attending an emergency department in Saudi Arabia and in the United Kingdom. Int J Clin Pharm. 2013;35(3):327-31.

2. Middleton J, McGrail S, Stringer K. Drug related deaths in England and Wales. BMJ. 2016;355:i5259

3. DenBemt PMLAV, Egberts TCG, DeJong DLTWV, Brouwers JRBJ. Drug-related problems in hospitalised patients. Drug Safety. 2000;22(4):321-33.

4. DenBemt PMV, DenBemt PMV, Egberts TC, DeJong DBLTV, DeJong DBLTV, et al. Drug-related problems in hospitalised patients. Drug Saf. 2000;22(4):321-33.

5. Bootman J, Johnson JA. Drug-related morbidity and mortality: A cost-of-illness model. Arch Intern Med. 1995;155(18):1949-56.

6. Alomi YA, Al-shaibani AS, Alfaisal G, Alasmi NM. Cost Analysis of Drug-related Problems in Saudi Arabia: Patients' and Healthcare Providers' Perspective. J Pharm Pract Community Med. 2018;4(2):107-12.

7. ASHP. ASHP Statement on Pharmaceutical Care. Am J Hosp Pharm. 1993;50:1720-3

8. American Society of Health-System Pharmacists. ASHP guidelines on a standardized method for pharmaceutical care. Am J Heal Pharm. 1996;53(14):1713-

9. Alomi YA, Almudaiheem HY. Clinical and Economic Outcomes of Pharmacist Intervention During Therapeutic Drug Monitoring Program in Saudi Arabia. Value Heal. 2016;19(7):A465-6.

10. Alomi YA, Fallatah AO, Al-Smail EH. Assessment of Clinical and Economic Outcomes of Pharmacist Intervention in Total Parenteral Nutrition Program in Saudi Arabia. Value Heal. 2016;19(7):A465

11. Alomi YA, Al-Shubbar NA, Lubad NA. Economics outcomes of medication safety program at public hospital in Riyadh, Saudi Arabia. In: Value in Heal. 2017;20(5):A32-A32

12. Alomi YA, El-Bahnasawi M, Elemam Al, Elgaili SH, Kamran M. Clinical and Economic Impact of Pharmacist Intervention at Critical Care of Private Hospital in Riydah, Saudi Arabia. Value Heal. 2016;7(19):A465

13. Alomi YA, Alghamdi SJ, Alattyh RA. Strategic Plan of General Administration of Pharmaceutical Care at Ministry of Health in Saudi Arabia 2012-2022. J Pharm Pharm Scien. 2015;1(13):1-8.

14. Alomi Y. National Pharmacy Administration Programs. BAOJ Pharm Sci. $2015 ; 1(2): 1-2$

15. Alomi YA, Alghamdi SJ, Alattyh RA, Elshenawy RA. The Evaluation of Pharmacy Strategic Plan in Past 2013-2016 and Forecasting of New Vision 2030 at Ministry of Health in Saudi Arabia. J Pharm Pract Community Med. 2018;4(2):93-101.

16. McDonough R. Writing a Business Plan for a New Pharmacy Service. The Dynamics of Pharmaceutical Care: Enriching Patients' Health. 2010;23.

17. Harris IM, Baker E, Berry TM, Halloran MA, Lindauer K, Ragucci KR, et al. Developing a Business-Practice Model for Pharmacy Services in Ambulatory Settings. Pharmacotherapy. 2008;28(2):7e-34e.

18. Sachdev G. Sustainable business models: Systematic approach toward successful ambulatory care pharmacy practice. Am J Heal Pharm. 2014;71(16):1366-74.

19. PMBOK Guide. A Guide to the Project Management Body of Knowledge. Sixth Edit. Project Management Institute, Inc. 2017.

20. Government of Saudi Arabia. Saudi Arabia Vision 2030. 2016. Available from: https://vision2030.gov.sa/sites/default/files/report/Saudi_Vision2030_EN_2017. pdf. 
Appendix (1).

$\underline{\text { PHARMACIST Note }}$

Patient Name:

Age.

Sex

Diagnosis:

Bed No

Section:

The intervention due to

( ) Over Dose

( ) Drug - Drug Interaction

( ) Not enough drug therapy

( ) No justifications for the drug uses

\section{$\underline{\text { Type of Intervention }}$}

( ) Discontinue Drug

( ) Change Drug

( ) Add Drug

Dear prescribing Dr

Pharmacist Name and Signature

Response:

( ) Agree ( ) Not agree ( ) TO be discuses please

Return to pharmacy:

Thank you for cooperation for better patient care
( ) Sub therapeutic Dose

( ) Drug not available

( ） Un necessary

( ) Not suitable admin. Rout

( ) Others 